\title{
Spontaneous intraperitoneal hemorrhage as the initial presentation of a gastrointestinal stromal tumor: a case report
}

\author{
Benjamin B. Freeman • Jonathan F. Critchlow • \\ Steven Cohen • Jonathan A. Edlow
}

Received: 18 July 2009 / Accepted: 4 November 2009 /Published online: 4 February 2010

(C) Springer-Verlag London Ltd 2010

\begin{abstract}
Background Spontaneous hemoperitoneum is rare. The most common etiologies are gynecologic, splenic, and hepatic. Gastrointestinal stromal tumors (GISTs) are commonly associated with intraluminal bleeding, but rarely with spontaneous hemoperitoneum. We report a case of spontaneous hemoperitoneum caused by a gastric GIST.

Case report A 54-year-old male presented with the acute onset of abdominal pain and a drop in hemoglobin. Subsequent evaluation, including a CT, MRI, and EUS, revealed a 1.2-cm mass along the greater curvature of the
\end{abstract}

\section{B. B. Freeman}

Department of Internal Medicine,

Robert Wood Johnson University Hospital,

1 Robert Wood Johnson Place,

New Brunswick, NJ, USA

\section{J. F. Critchlow}

Department of Surgery,

Beth Israel Deaconess Medical Center,

300 Brookline Avenue,

Boston, MA, USA

\section{S. Cohen}

Department of Medicine (Gastroenterology),

Beth Israel Deaconess Medical Center,

Needham campus,

Needham, MA, USA

\section{J. A. Edlow}

Department of Emergency Medicine,

Beth Israel Deaconess Medical Center,

300 Brookline Avenue,

Boston, MA, USA

B. B. Freeman $(\bowtie)$

518 Trinity Place,

Westfield, NJ 07090, USA

e-mail: Benfr41@gmail.com stomach and associated hemoperitoneum. The patient was taken electively to the operating room for laparoscopic removal of the mass. Pathology confirmed that it was a GIST.

Conclusion GIST is a rare clinical entity that infrequently presents with spontaneous hemoperitoneum. Emergent treatment should be guided towards treating the spontaneous hemoperitoneum.

Keywords GIST · Spontaneous hemoperitoneum · Intraperitoneal hemorrhage

\section{Introduction}

Spontaneous hemoperitoneum is a rare and potentially lifethreatening entity with an extensive differential diagnosis (Table 1). Gynecologic, splenic, and hepatic etiologies are the most common $[1,2]$.

Important gynecologic causes of spontaneous hemoperitoneum include ruptured ectopic pregnancy, ruptured ovarian cyst, and endometriosis [1,2]. Rare gynecologic causes of spontaneous hemoperitoneum include various benign and malignant neoplasms [3], hemorrhagic corpus luteum cyst torsion [2], and spontaneous uterine rupture in the first trimester of pregnancy [4].

Splenic causes of spontaneous hemoperitoneum include oncologic etiologies such as chronic myelomonocytic leukemia [5], as well as infectious etiologies, such as infectious mononucleosis [6], cytomegalovirus, EpsteinBarr virus, malaria, and rarely Bartonella henselae [1, 2]. In addition, spontaneous splenic rupture is commonly associated with an underlying mass, most commonly a hamartoma [2], or with infiltrative diseases such as amyloidosis and Gaucher's disease [2]. 
Table 1 Differential diagnosis of spontaneous intraperitoneal hemorrhage

\begin{tabular}{|c|c|}
\hline Organ system & Differential diagnosis \\
\hline Gynecological & $\begin{array}{l}\text { Ectopic pregnancy } \\
\text { Ruptured ovarian cyst } \\
\text { Uterine leiomyoma/leiomyosarcoma } \\
\text { Ovarian granulosa cell tumor } \\
\text { Ruptured corpus leuteum cyst } \\
\text { Hyperemesis gravidarum } \\
\text { Endometriosis } \\
\text { Spontaneous uterine rupture }\end{array}$ \\
\hline Splenic & $\begin{array}{l}\text { Chronic myelomonocytic leukemia } \\
\text { Infectious mononucleosis } \\
\text { Spontaneous splenic rupture } \\
\text { Iatrogentic } \\
\text { Spontaneous rupture of splenic vein } \\
\text { Torsion and rupture of wandering spleen } \\
\text { Hamartoma } \\
\text { Primary splenic angiosarcoma }\end{array}$ \\
\hline Hepatic & $\begin{array}{l}\text { Peliosis hepaticus } \\
\text { Hepatic adenoma/adenomatosis } \\
\text { Hepatocellular carcinoma } \\
\text { Hemangioma } \\
\text { Primary hepatic angiosarcoma } \\
\text { Metastatic cancer } \\
\text { Amyloid } \\
\text { Focal nodular hyperplasia }\end{array}$ \\
\hline Biliary & $\begin{array}{l}\text { Ruptured cholangiocarcinoma } \\
\text { Transhepatic rupture of gallbladder }\end{array}$ \\
\hline Vascular & $\begin{array}{l}\text { Ruptured cystic artery pseudoaneurysm } \\
\text { Ruptured splenic artery aneurysm } \\
\text { Segmental mediolytic arteriopathy }\end{array}$ \\
\hline Gastric & $\begin{array}{l}\text { Mixed cavernous-capillary hemangioma } \\
\text { GIST }\end{array}$ \\
\hline Colonic & $\begin{array}{l}\text { Meckel's diverticulitis } \\
\text { GIST }\end{array}$ \\
\hline Pancreatic & Ruptured pseudocyst \\
\hline Miscellaneous & Ruptured benign solitary fibrous tumor \\
\hline
\end{tabular}

Rupture of a previously unknown liver lesion, although rare, is a common cause of spontaneous hemoperitoneum $[1,2]$. Hepatic adenomas, the most common benign liver lesion associated with spontaneous hemoperitoneum, are most frequently encountered in young females taking oral contraceptives or who are pregnant $[1,2]$. Other benign liver lesions known to cause spontaneous hemoperitoneum include giant hemangiomas [1], focal nodular hyperplasia $[1,2]$, and hepatic adenomatosis, an uncommon condition resulting in multiple large hepatic adenomas not associated with oral contraceptive use [7]. Hepatic amyloidosis rarely causes spontaneous hemoperitoneum $[1,2]$. Hepatocellular carcinoma (HCC) is the most common malignant hepatic mass causing spontaneous hemoperitoneum, and is associated with a high mortality $[1,2]$. Primary hepatic angiosarcoma is much less likely to bleed than carcinoma [2]. Occasionally, metastatic cancer to the liver causes spontaneous hemoperitoneum $[1,2]$.

\section{Case report}

A 54-year-old male physician in good health developed the acute onset of upper abdominal pain over 15 min after playing basketball. The pain was moderate in intensity and did not radiate to the back. Over the next $12 \mathrm{~h}$, the pain became significantly more intense, but the patient declined to seek medical advice. After the pain persisted at the same intensity for 3 days and became more diffuse, the patient went to an Emergency Department. The patient denied fever, anorexia, nausea, vomiting, diarrhea, constipation, or hemodynamic symptoms. Past medical history was noncontributory. He had no prior abdominal operations.

In the Emergency Department, the patient's vital signs were normal, and he was in no apparent distress. The physical examination was normal except for moderate diffuse abdominal tenderness with rebound tenderness bilaterally at the upper quadrants. Bowel sounds were normoreactive. The stool was brown and guaiac negative.

Laboratory testing was notable for a hemoglobin of 12.3 (known baseline of 14), a WBC of 10.8, and a slightly elevated amylase of 245. Otherwise, the $\mathrm{CBC}$, electrolytes, liver function testing, and urinalysis were normal. A CT scan of the abdomen revealed hemoperitoneum along the

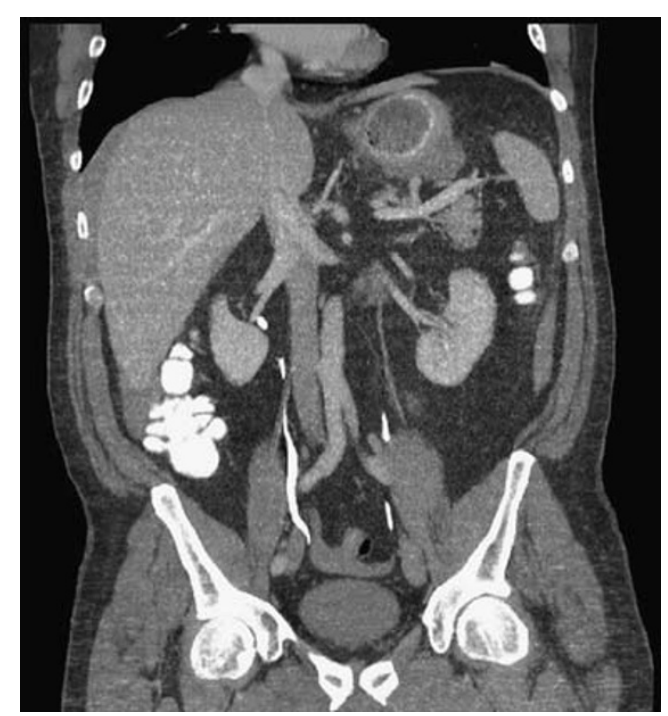

Fig. $1 \mathrm{CT}$ scan of the abdomen revealing hemoperitoneum along the stomach 
stomach (Fig. 1). Surgery was consulted, but the patient left against medical advice. The next morning, the patient saw a surgeon as an outpatient. His repeat hemoglobin at this point was 11.6, and his amylase had dropped to 125 . The surgeon's plan was to proceed with laparotomy. The patient was reluctant and sought the opinion of another surgeon. Since the patient had been stable for 4 days, the plan was to observe over time, with the rationale that if surgery could be delayed, a successful laparoscopic intervention was more likely. The hemoglobin nadired at 10.2, and by 7 days after the onset of pain, the patient was entirely asymptomatic.

At day 25, an MRI showed a resolving hemoperitoneum and a $1.2-\mathrm{cm}$ lesion along the greater curvature of the stomach. At this point, the decision was made to perform a laparoscopic resection approximately 6 weeks later, when the hemoperitoneum would be mostly resolved. One week prior to surgery, gastroscopy with endoscopic ultrasound was performed. The ultrasound showed a blood vessel coursing through a submucosal mass, which was thought most likely to be a GIST.

At operation, the patient was found to have a $<2 \mathrm{~cm}$ irregularly shaped mass in the mid-portion of the greater curvature of the stomach. There was no other possible etiology for the hemoperitoneum. This mass was resected using standard stapling techniques with clear margins. Pathology later revealed a C-kit-positive tumor consistent with a GIST. The tumor was $1.3 \mathrm{~cm}$ and had a mitotic index of up to 10 per high powered field. Because of concern about tumor rupture at presentation, the patient was started on adjuvant imatinib mesylate (Gleevac). He has remained free of macroscopic disease for 18 months.

\section{Discussion}

Causes of spontaneous hemoperitoneum are varied, but initial Emergency Department treatment should be directed at emergent therapies. Beside the common causes discussed earlier, less common causes include ruptured cystic artery pseudoaneurysm [8], ruptured splenic artery aneurysm [9], and spontaneous variceal rupture due to portal hypertension $[1,2]$. Anticoagulation, either due to medication or as a result of congenital blood dyscrasias, can lead to spontaneous hemoperitoneum $[1,2]$. Segmental mediolytic arteriopathy, a rare condition of unknown etiology, can involve the colic, mid-jejunal, common hepatic, intrahepatic, and gastric arteries, causing intraperitoneal bleeding [10]. A benign solitary fibrous tumor, which was once considered to be an exclusively thoracic lesion, can also cause hemoperitoneum [11]. Ruptured cholangiocarcinomas can rarely present with spontaneous hemorrhage [12]. A mixed cavernous-capillary hemangioma with central necrosis can occur on the greater curvature of the stomach, accompanied by bleeding and hemoperitoneum [13]. Other rare conditions associated with hemoperitoneum include transhepatic rupture of the gall bladder, which has been described fewer than 20 times in the literature [14]. Intraperitoneal hemorrhage can also be caused by inflammation of a nonperforated Meckel's diverticulum [15]. Pancreatic pseudocyst is an unusual entity of acute abdomen, usually occurring among alcoholics [16].

Gastrointestinal stromal tumors (GISTs) are rare, accounting for only $0.1-3 \%$ of all gastrointestinal malignancies [1719]. The annual incidence of GIST in the US is 4,500 to 6,000 cases per year, or roughly 10 to 20 cases per million people per year $[19,20]$. The median age at diagnosis of a GIST is $60[19,20]$. Primary GISTs arise most commonly in the stomach $(50-70 \%)$, followed by the small intestine (25$35 \%)$, colon and rectum $(5-10 \%)$ and esophagus $(<5 \%)$ [21]. Gastric GISTs arise most commonly in the fundus. The clinical presentation of gastric GISTs is varied. Small GISTs $<2 \mathrm{~cm}$ are generally asymptomatic and are often detected incidentally. Large GISTs can ulcerate and present with gastrointestinal bleeding [22-25]. Other common symptoms of GISTs include anorexia, weight loss, nausea, vomiting, early satiety, bloating, and abdominal pain.

Although it is common for GISTs to present with intraluminal bleeding [22-25], GISTs presenting with spontaneous hemoperitoneum are rare. We could only find one other case report in the literature of a GIST presenting with hemoperitoneum [26]. Hepatic metastases of a GIST can spontaneously rupture, producing hemoperitoneum [27]. Primary GISTs of the transverse mesocolon have been associated with hemorrhagic shock caused by rupture of the tumor [28].

\section{Conclusion}

The differential diagnosis of spontaneous intraperitoneal hemorrhage is broad. GIST is a rare possible etiology. Emergent management of a patient presenting with spontaneous hemoperitoneum involves surgical consultation and resuscitation as necessary. The patient presented in this case report did well with non-operative management followed by surgical resection.

\section{References}

1. Lucey BC, Varghese JC, Anderson SW, Soto JA (2007) Spontaneous hemoperitoneum: a bloody mess. [Review] [43 refs] [Journal Article. Review]. Emerg Radiol 14(2):65-75

2. Lucey BC, Varghese JC, Soto JA (2005) Spontaneous hemoperitoneum: causes and significance. [Review] [50 refs] [Journal Article. Review]. Curr Probl Diagn Radiol 34(5):182-195 
3. Elbiss HM, Neale E (2006) Uterine leiomyosarcoma mimicking a ruptured aortic aneurysm. [Case Reports. Journal Article]. J Obstet Gynaecol 26(1):85-86

4. Park YJ, Ryu KY, Lee JI, Park MI (2005) Spontaneous uterine rupture in the first trimester: a case report. [Case Reports. Journal Article] Journal of Korean Medical. Science 20(6):1079-1081

5. Goddard SL, Chesney AE, Reis MD, Ghorab Z, Brzozowski M, Wright FC, Wells RA (2007) Pathological splenic rupture: a rare complication of chronic myelomonocytic leukemia. [Case Reports. Journal Article]. Am J Hematol 82(5):405-408

6. Brichkov I, Cummings L, Fazylov R, Horovitz JH (2006) Nonoperative management of spontaneous splenic rupture in infectious mononucleosis: the role for emerging diagnostic and treatment modalities. [Case Reports. Journal Article]. Am Surg 72 (5):401-404

7. Arvind N, Duraimurugan D, Rajkumar JS (2006) Hepatic adenomatosis-a rare double complication of multiple adenoma rupture and malignant transformation. [Case Reports. Journal Article]. Indian J Gastroenterol 25(4):209-210

8. Ghoz A, Kheir E, Kotru A, Halazun K, Kessel D, Patel JJ, Lodge JP (2007) Hemoperitoneum secondary to rupture of cystic artery pseudoaneurysm. [Case Reports. Journal Article]. Hepatobiliary \& Pancreatic Diseases International 6(3):321-323

9. Powari M, Widdison A, Mathew J (2007) Acute haemoperitoneum: a surgical emergency due to a rare cause of ruptured splenic artery aneurysm. [Case Reports. Letter]. Pathology 39(1):185-187

10. Rosenfelder NA, Taylor-Robinson SD, Jackson JE, Stamp GW. Segmental mediolytic arteriopathy in a patient with intraperitoneal bleeding. [Review] [10 refs] [Case Reports. Journal Article. Research Support, Non-U.S.

11. Patriti A, Rondelli F, Gulla N, Donini A (2006) Laparoscopic treatment of a solitary fibrous tumor of the greater omentum presenting as spontaneous hemoperitoneum. [Case Reports. Journal Article]. Ann Ital Chir 77(4):351-353

12. Chong RW, Chung AY, Chew IW, Lee VK (2006) Ruptured peripheral cholangiocarcinoma with hemoperitoneum. [Case Reports. Journal Article]. Dig Dis Sci 51(5):874-876

13. Lin CH, Hsieh HF, Yu JC, Hsu SD, Chen CW, Liao GS, Hsieh CB (2006) Spontaneous rupture of a large exogastric hemangioma complicated by hemoperitoneum and sepsis. [Case Reports. Journal Article]. J Formos Med Assoc 105(12):1027-1030

14. Kolder D, Geiger T, Tharakan AK, Kessel JW, Awad ZT (2006) Massive hemoperitoneum from transhepatic perforation of the gallbladder. [Case Reports. Journal Article]. Mt Sinai J Med 73 (8):1135-1136

15. Burt BM, Tavakkolizadeh A, Ferzoco SJ (2006) Meckel's hemoperitoneum: a rare case of Meckel's diverticulitis causing intraperitoneal hemorrhage. [Case Reports. Journal Article]. Dig Dis Sci 51(9):1546-1548
16. Chiu HH, Chen CM, Wang KC, Lu YY, Mo LR (2006) Pancreatic pseudocyst bleeding associated with massive intraperitoneal hemorrhage. [Case Reports. Journal Article]. Am J Surg 192 (1):87-88

17. Nilsson B, Blumberg P, Meis-Kinblom JM et al (2005) Gastrointestinal stromal tumors: the incidence, prevalence, clinical course, and prognostication in the preimatinib mesylate era- a population basesd study in western Sweeden. Cancer 103:821

18. Kindblom LG, Meis-Kindblom JM, Blumming P et al (2003) Incidence, prevalence, phenotype, and biologic spectrum of gastrointestinal stroma tumors (GIST): a population-based study [abstract]. Ann Oncol 13:157

19. Demetri GD, Morgan JA (2005) Gastrointestinal stromal tumors, leiomyomas, and leiomyosarcomas of the gastrointestinal tract. UpToDate

20. Lewis JJ, Brennan MF (1996) Soft tissue sarcomas. Curr Probl Surg 33:817-872

21. Miettinen M, Lasota J (2001) Gastrointestinal stromal tumors: definition, clinical, histological, immunohistochemical, and molecular genetic features and differential diagnosis. Virchows Arch 438:1-12

22. Tryggvason G, Kristmundsson $\mathrm{T}$, Orvar K, Jonasson JG, Magnusson MK, Gislason HG (2007) Clinical study on gastrointestinal stromal tumors (GIST) in Iceland, 1990-2003. [Journal Article]. Digestive Diseases \& Sciences 52(9):2249-2253

23. Djukic V, Karamarkovic A, Mijatovic S, Micev M, Bumbasirevic V, Djurovic M, Stepic D, Jeremic V, Popovic N, Sijacki A, Krsic S, Gregoric P (2007) [Gastrointestinal gastric tumor (GIST) as a cause of massive hemorrhage from the upper digestive tract]. [Serbian] [Case Reports. English Abstract. Journal Article]. Acta Chir Iugosl 54(1):169-171

24. Ebrahimi K, Velickovic D, Spica B, Sabljak P, Bjelovic M, Stojakov D, Micev M, Dunjic M, Pesko P (2007) [Gastrointestinal stromal tumors (GIST) of the stomach as a cause of upper gastrointestinal bleeding]. [Serbian] [English Abstract. Journal Article]. Acta Chir Iugosl 54(1):115-118 UI: 17633870

25. Darnell A, Dalmau E, Pericay C, Musulen E, Martin J, Puig J, Malet A, Saigi E, Rey M (2006) Gastrointestinal stromal tumors [Journal Article]. Abdom Imaging 31(4):387-399

26. Kim TH, Choi SC, Choi CS, Nah YH (2006) Hemoperitoneum secondary to a ruptured gastric stromal tumor. Gastrointest Endosc 63(7):1066-1067 discussion 1067. Epub 2006 Apr 3

27. Cegarra-Navarro MF, de la Calle MA, Girela-Baena E, GarciaSantos JM, Lloret-Estan F, de Andres EP (2005) Ruptured gastrointestinal stromal tumors: radiologic findings in six cases. Abdom Imaging 30(5):535-542

28. Jacobs K, de Gheldere Ch, Vanclooster P (2006) A ruptured gastrointestinal stromal tumour of the transverse mesocolon: a case report. [Case Reports. Journal Article]. Acta Chir Belg 106(2):218-221 